\title{
Pendidikan Karakter Melalui Seni Teater Berbasis Kearifan Lokal Secara Daring untuk Anak-Anak Kampung Kumuh Pasar Keramat
}

\author{
Arif Sadikin Purnama', Mafta Kresna Ma'arifarsyah', ${ }^{1}$ Putri Rahayu Nengsih², Dewi \\ Desiana $^{2}$,Yusuf Guntur Hari Putra ${ }^{1}$ Gita Anggraini ${ }^{3}$ \\ ${ }^{1}$ Pendidikan Matematika, Pendidikan, STKIP Muhammadiyah Sampit \\ ${ }^{2}$ Pendidikan Ekonomi, Pendidikan, STKIP Muhammadiyah Sampit \\ Bimbingan dan Konseling, STKIP Muhammadiyah Sampit \\ Email: purnamaarifsadikin7@gmail.com
}

\begin{abstract}
Abstrak
Keramat merupakan nama salah satu pasar di Kota Sampit yang mayoritas dihuni penduduk perekonomian menengah ke bawah. Terletak di area padat serta limbah pembuang pasar langsung ke sungai yang mengalir di bawah rumah-rumah penduduk disertai sampah yang nampak berserakan di aliran sungai tersebut menyebabkan pemukiman terlihat sangat kumuh. Aktivitas sehari-hari anak-anak di sini harus berbaur dengan limbah pasar dan sungai yang kurang sehat untuk mandi maupun bermain. Sering membuah sampah sembarangan, berkelahi, dan tidak peduli terhadap lingkungannya adalah pemandangan sehari-hari yang ditampakkan anak-anak disini. Metode yang digunakan dalam pengabdian ini menggunakan tiga tahap yaitu tahap awal, tahap inti dan tahap akhir, setiap tahapan memiliki langkahlangkah pelaksanaan. Pengabdian masyarakat ini merupakan kegiatan Program Kreativitas Mahasiswa (PKM) tahun 2020. Fokus kegiatan ini adalah menanamkan pendidikan karakter kepada anak-anak kampung keramat dengan menggunakan seni teater. Teater juga dimaksudkan untuk mewadahi anak-anak Pasar Keramat dalam mengembangkan potensi yang mereka miliki. Sehubungan dengan adanya covid-19, kegiatan yang awalnya direncanakan luring berubah menjadi daring. Media yang digunakan dalam pelaksanaan kegiatan adalah WA Grup, Instagram, dan YooTUbe. Melalui kegiatan ini telah dihasilkan buku pedoman pelaksanaan, kompilasi video pembelajaran, audio sinematik cerita rakyat, serta artikel ilmiah. Anak-anak pasar keramat antusias mengikuti kegiatan dan memberikan umpan balik yang positif.
\end{abstract}

Kata Kunci: Pasar Keramat, Teater, Pendidikan Karakter

\begin{abstract}
Keramat is the name of one of the markets in Sampit City which is mostly inhabited by the middle to lower economic population. Located in a congested area and market dumping waste directly into the river that flows under people's houses along with garbage that seems scattered in the river flow makes the settlement look very shabby. The children's daily activities here have to mingle with market waste and unhealthy rivers for bathing and playing. Often littering, fighting, and not caring about the environment are the daily sights of the children here. The method used in this service uses three stages, namely the initial stage, the core stage and the final stage, each stage has implementation steps. This community service is an activity of the Program Kreativitas Mahasiswa (PKM) in 2020. The focus of this activity is to instil character education for children of sacred villages by using theatre arts. Theatre is also intended to accommodate the children of the Keramat Market in developing their potential.
\end{abstract}


Due to the existence of Covid-19, activities that were originally planned to be offline have turned online. The media used in carrying out activities are the WhatsApp Group, Instagram, and Youtube. Through this activity, implementation manuals have been produced, a compilation of instructional videos, cinematic audios of folk tales, and scientific articles. The children of the sacred market were enthusiastic about participating in the activity and gave positive feedback.

Keywords: Keramat Market, Theatre, Character Education

\section{PENDAHULUAN}

Anak-anak yang menjadi sasaran pengabdian kepada masyarakat ini adalah anak-anak pasar tradisional di Kota Sampit yaitu pasar keramat, di sekitar Pasar Kramat terdapat satu pemukiman warga yang secara geografis terletak di jalan Biak Inhutani 3 serta berdekatan dengan Taman Kota Sampit. Walaupun berada di dalam kota, masih banyak orang sampit sendiri yang belum mengetahui pemukiman ini. Terletak di area pasar menyebabkan pemukiman terlihat sangat kumuh, sampah-sampah berserakan di sekitar sungai yang mengalir di bawah rumah-rumah penduduk. Rata-rata rumah penduduk terbuat dari kayu dengan fasilitas sanitasi yang masih minim. Untuk keperluan mandi dan sanitasi sehari-hari mereka mengandalkan sungai tersebut.

Kondisi anak-anak di kampung ini sebagian besar memang telah mengenyam pendidikan di sekolah. Namun ada beberapa juga yang menganggap sekolah itu tidak penting dan membosankan. Anak yang tidak sekolah mengisi harinya dengan mengamen dan membantu orang tua. Sore hari mereka menghabiskan waktu dengan bermain di sungai yang sangat kumuh di sekitar rumah mereka. Bahkan saat kami melakukan observasi, anak-anak tersebut mengajak untuk mengikuti mereka bermain dan mandi di sungai. Sedangkan para orang tua yang sibuk bekerja dan lelah dengan aktivitas perekonomian tidak mempunyai waktu untuk banyak menanamkan karakter kepada anak-anak mereka. Belum lagi ditambah dengan lingkungan, dan kebiasaan keseharian mereka. Oleh sebab itu, para orang tua dan anak-anak di kampung ini sangat gembira saat tim pelaksana kegiatan menawarkan solusi untuk pengembangan karakter anak-anak di daerah Pasar Keramat melalui seni teater. Menurut mereka kesenian tidak membosankan dan bisa mengembangkan potensi terpendam yang mereka miliki.

Seni teater dipilih karena melihat potensi masyarakat sasaran, dan latar belakang tim yang aktif dalam kegiatan teater. Teater juga dinilai efektif untuk memasukkan nilai karena bersifat menarik minat dan perhatian (Saleh, 1967: 310). Masih menurut Saleh, melalui teater seorang lakon berkesempatan untuk menemukan jati dirinya (Saleh, 1967: 213). Sebenarnya teater juga telah lama dijadikan sebagai salah satu metode pembelajaran yang dikenal sebagai metode sosiodrama. Pelatihan teater merupakan penggabungan dari pelatihan teknis dan psikologis. Pada dasarnya teknik-teknik yang digunakan sudah menjadi pola latihan teater secara umum. Hal ini disebabkan teater menyangkut keterampilan tubuh dan keterampilan kejiwaan (Juned, 2012). Drama (teater) sebagai metode pembelajaran strategis karena bersifat permainan, memberikan pengertian baru, berlatih gerak irama, menyesuaikan kata dengan pikiran, rasa, kemauan, dan tenaga, mengajarkan adat sopan santun dan seterusnya (Srisudarso \& Nurhasanah, 2018). Teater adalah visualisasi dari drama atau drama yang dipentaskan di atas panggung dan disaksikan oleh penonton (Eko Santoso, dkk, 2008). Adapun jenis cerita yang dikembangkan dalam teater ini nantinya adalah cerita-cerita yang mengandung kearifan lokal yang berkembang dalam masyarakat Sampit Kalimantan Tengah, 
dengan tujuan dari kegiatan PKM ini menanamkan pendidikan karakter kepada anak-anak kampung keramat dengan menggunakan seni teater.

\section{METODE}

Kegiatan pengabdian masyarakat di Pasar Keramat ini dilaksanakan selama dua bulan mulai dari Bulan September sampai dengan bulan Oktober tahun 2020. Kegiatan ini merupakan kegiatan Program Kreativitas Mahasiswa (PKM) yang dilaksanakan oleh Tim Teater Keramat yang beranggotakan 5 orang mahasiswa dari STKIP Muhammadiyah Sampit, dengan seorang dosen pembimbing. Adapun tahapan pelaksanaan kegiatan adalah sebagai berikut:

a. Tahap Awal, terdiri atas:

1) Penyesuaian rencana pelaksanaan kegiatan dengan kebijakan baru di masa pandemi yang berbasis pada aktivitas daring. Pada kegiatan ini tim melakukan beberapa penyesuaian, diantaranya penyesuaian jadwal, teknik pelaksanaan, anggaran kegiatan, serta tempat dan media pelaksanaan.

2) Penyusunan jadwal rinci dan penanggung jawab kegiatan. Tim melakukan penyusunan ulang jadwal dan menetapkan penanggung jawab setiap kegiatan.

3) Penyusunan silabus. Silabus ini disusun agar kegiatan tidak hanya sebagai kegiatan kesenian saja, tetapi mengandung unsur pendidikan karakter.

4) Menyiapkan alat untuk kegiatan berbasis daring.

b. Tahap Inti

1) Pembuatan Buku Pedoman Pelaksanaan Program. Buku pedoman berfungsi sebagai panduan dalam melaksanakan kegiatan untuk masyarakat sasaran.

2) Melakukan kegiatan pembelajaran dengan materi: pengenalan teater, latihan dasar konsentrasi, olah empat ranah (pernapasan, vokal, rasa dan tubuh). Olah empat ranah terdiri atas olah vokal, olah pernafasan, olah rasa dan olah tubuh, keaktoran, pengenalan cerita dan karakter. Setiap materi tersebut memiliki kandungan nilai-nilai karakter yang ingin ditanamkan kepada anak-anak kampung keramat. Semua kegiatan dilakukan secara daring, serta menaati protokol kesehatan.

3) Pemilihan Aktor. Pada tahap ini tim melakukan pemilihan aktor untuk persiapan pementasan secara daring. Anak-anak akan diseleksi untuk mendapatkan pemeran yang sesuai karakter. Pada tahap ini juga ditanamkan karakter kreatif dan jiwa kompetitif.

4) Penggarapan Naskah Pementasan Teater Secara Daring. Naskah disusun oleh tim pelaksana dan dilakukan secara daring melalui zoom.

5) Pementasan. Pada tahap ini tim akan melaksanakan pementasan sederhana bersama anak-anak Pasar Keramat dan tim pelaksana menggunakan media zoom.

c. Tahap Akhir

Tahap akhir dari kegiatan ini adalah evaluasi program dan penyusunan laporan akhir sebagai kegiatan akhir dari program ini. Kemudian dilanjutkan dengan penyusunan artikel dan mempublikasikannya. 


\section{HASIL}

Setelah melewati tahapan-tahapan di atas maka diperoleh hasil sebagai berikut:

a. Tersusunya silabus dan kurikulum Teater Keramat Sampit

Penyusunan silabus dan kurikulum sebagai bahan penyampaian materi kepada anakanak pasar keramat. Dengan adanya silabus dan kurikulum, kegiatan dapat dilaksanakan dengan tepat sasaran dan sesuai dengan pembelajaran mengenai seni teater

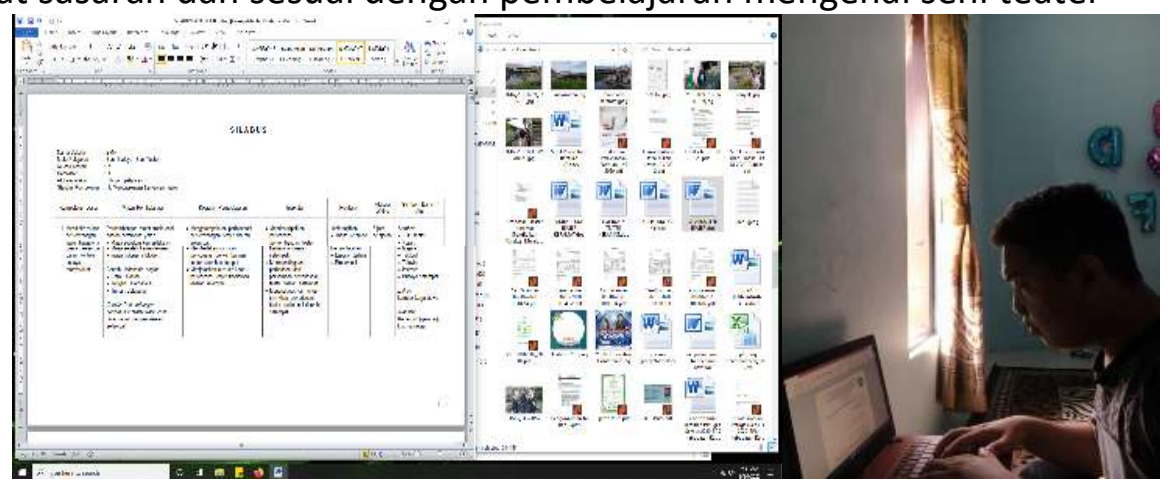

Gambar 1. Tim saat mengerjakan Silabus Teater

b. Kompilasi video pembelajaran

Video pembelajaran dibuat karena program ini dilaksanakan secara daring. Video berisi materi-materi pembelajaram yang telah dibuat di silabus. Video dibuat dengan memperhatikan aspek psikologis masayarakat sasaran. Bahasa yang digunakan dalam video dibuat sesederhana mungkin agar disukai oleh anak-anak. Video yang telah dibuat dan diedit kami kirim melalui grup whatsapp yanng beranggotakan anak-anak Pasar Keramat Sampit. Selain itu, kami juga memanfaatkan media sosial seperti instagram dan juga youtube sebagai sarana lain dalam mempublikasikan materi. Media sosial ini digunakan karena dapat mempermudah masyarakat sasaran untuk menyaksikan kembali video pembelajaran. Hal ini penting untuk mengatasi kendala HP yang memorinya sering penuh. Media sosial yang digunakan adalah Instagram dan Youtube. Tim pelaksana bergantian menjadi pengisi materi pembelajaran tersebut. Video pembelajaran yang telah dibuat adalah materi pengenalan teater, latihan konsentrasi, olah pernapasan, olah vokal dan olah tubuh.

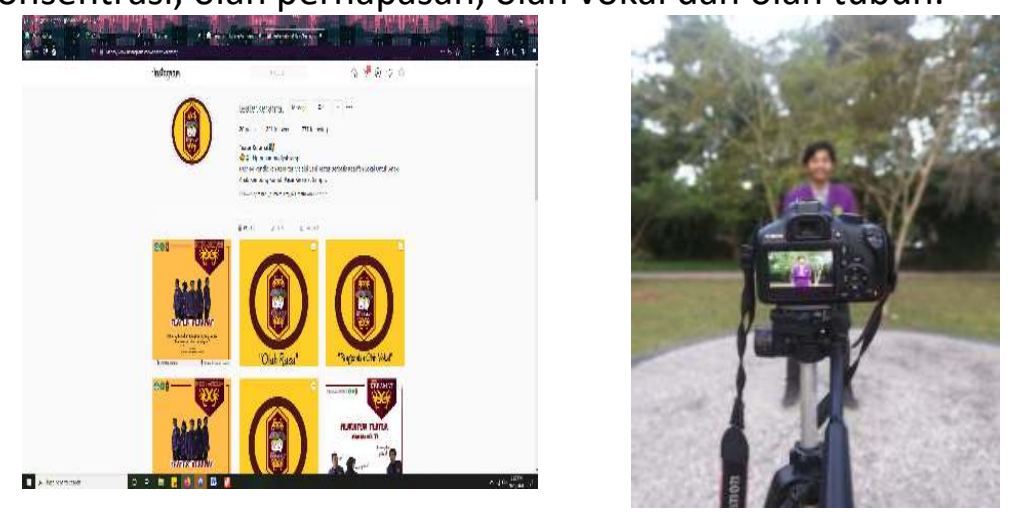

Gambar 2. Media sosial instagram dan Proses Pembuatan Video 


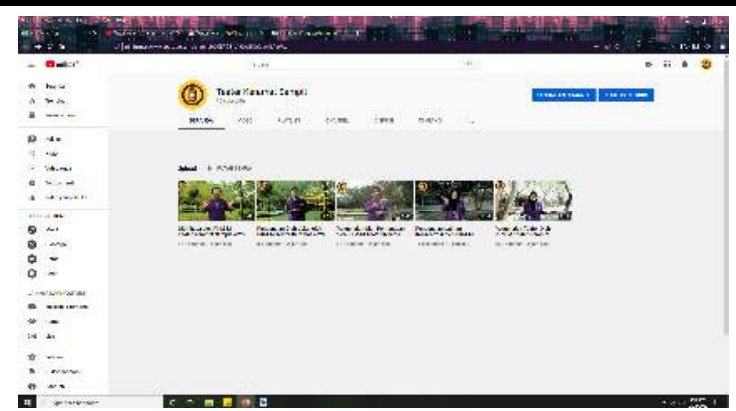

\section{Gambar 3. Channel Youtube Teater Keramat Sampit}

c. Audio sinematik cerita rakyat

Cerita-cerita rakyat Kotawaringin Timur dikemas menjadi audio senamatik dan di kirim ke wa grup anak-anak pasar keramat. Melalui audio ini diajarkan pendidikan karakter mengenai cinta lingkungan, jujur, disiplin, religius, kreatif, mencintai budaya dan peduli terhadap sesama. Tujuan lainnya adalah memperkenalkan anak-anak dengan kearifan lokal yang dimiliki oleh Kotawaringin Timur. Cerita-cerita di audio sinematik juga diunggah ke instagram dan channel youtube yang dimiliki tim teater keramat.

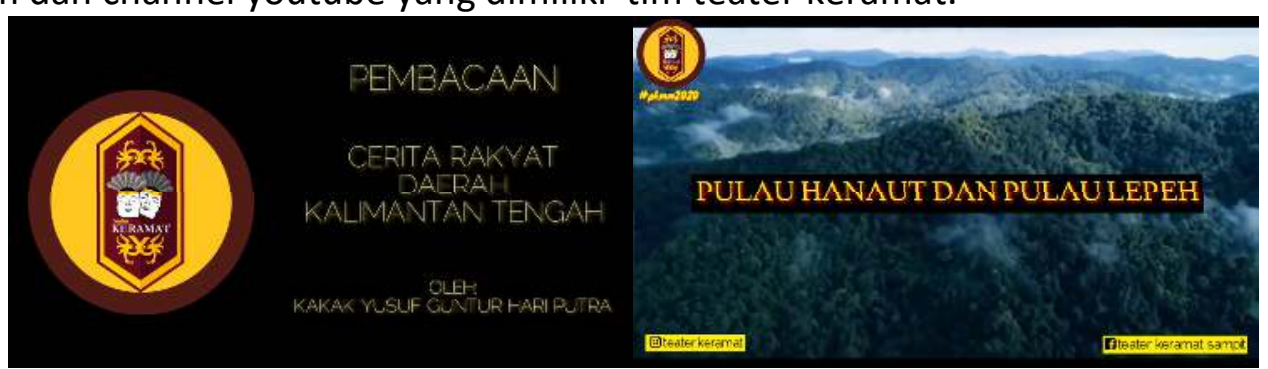

\section{Gambar 4. Audio Sinematik Cerita Rakyat Kotawaringin Timur}

d. Buku pedoman pelaksanaan kegiatan

Buku pedoman berisi tahapan kegiatan yang dilakukan tim teater keramat mulai dari tahap awal, tahap inti, dan tahap akhir kegiatan. Dalam buku pedoman juga dijelaskan teknis kegiatan serta media yang digunakan. Buku berfungsi agar masyarakat sasaran memahami program yang sedang dilakukan oleh tim pelaksana. Buku ini dikirimkan kepada masyarakat sasaran melalui grup whatsapp.

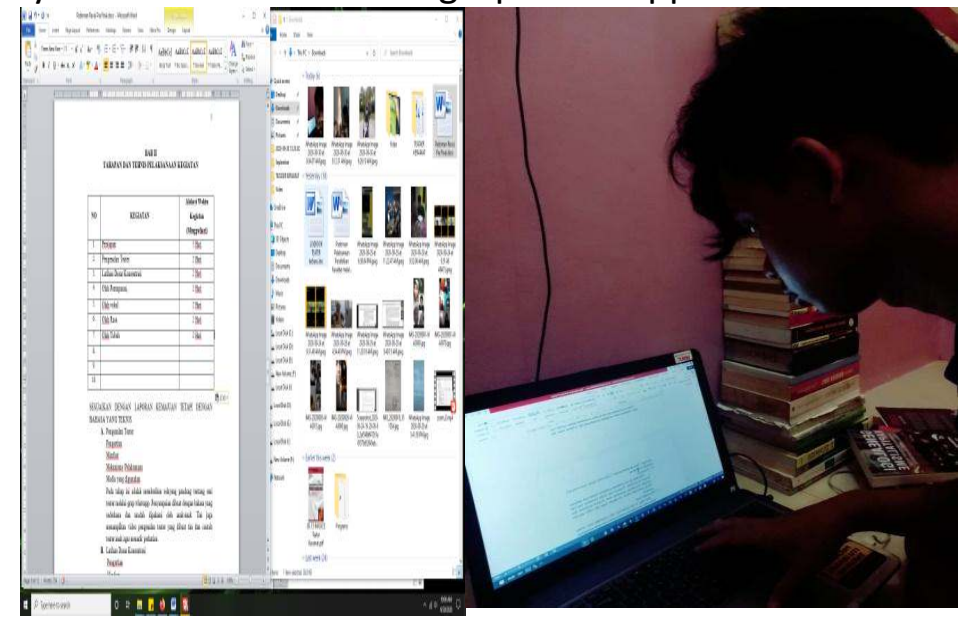

Gambar 5. Penyusunan Buku Pedoman 
e. Artikel Ilmiah, yaitu artikel yang dibuat berdasarkan kegiatan pengabdian masyarakat yang telah dilakukan. Artikel ini kemudian dipublikasikan ke jurnal agar dapat dibaca dan menjadi inspirasi pelaksana kegiatan lainnya.

\section{PEMBAHASAN}

Awalnya kegiatan pengabdian masyarakat ini direncanakan secara luring, seiring datangnya pandemi covid-19 kegiatan dilaksanakan secara daring. Sehingga tim pelaksana kegiatan melakukan penyesuaian kegiatan. Tim pelaksana dituntut untuk berinovasi dengan media-media digital dan mengemas pembelajaran secara digital juga. Kegiatan dilakukan secara daring untuk mencegah penyebaran covid-19 dan mengikuti himbauan pemerintah. Perubahan dari luring secara daring, menuntut tim pelaksana berinovasi. Agar kegiatan dapat terlaksana dengan baik tim pelaksana memaksimalkan penggunaan sosial media. Kegiatan pembelajaran dilakukan dengan memberikan materi-materi teater yang dikemas dalam video pembelajaran yang direkam terlebih dulu oleh tim pelaksana. Video ini kemudian disampaikan ke dalam grup WhatsApp serta diunggah ke sosial media Instagram dan YouTube. Pembuatan grup WhatsApp dipilih karena anak-anak masih asing terhadap aplikasi yang lain seperti zoom. Setelah mengunggah video pembelajaran tim pelaksana akan mengirimkan video pembelajaran ke grup WhatsApp dan menerangkan materi secara umum. Anak-anak kemudian menyaksikan video di rumah masing-masing serta mempraktekkan beberapa materi dan diminta untuk merekam aktivitas mereka.

Tanggapan anak-anak kampung keramat sebagai masyarakat terhadap program ini cukup positif. Mereka sangat antusias mengikuti setiap pembelajaran serta memberikan respon baik setiap materi yang disampaikan oleh tim pelaksana. Beberapa anak bahkan berinisiatif menghubungi tim pelaksana melalui pesan langsung untuk menanyakan materi selanjutnya. Melalui pembelajaran ini, mereka mulai menyukai dunia teater. Hal ini terlihat dari beberapa anak yang mengirimkan video mereka sedang bermain peran bersama temannya.

Untuk melakukan evaluasi terhadap kegiatan yang dilakukan, tim pelaksana kegiatan melakukan menyebarkan angket melalui google formulir kepada masyarakat sasaran. Hasil evaluasi cukup menggembirakan seperti diagram di bawah ini.

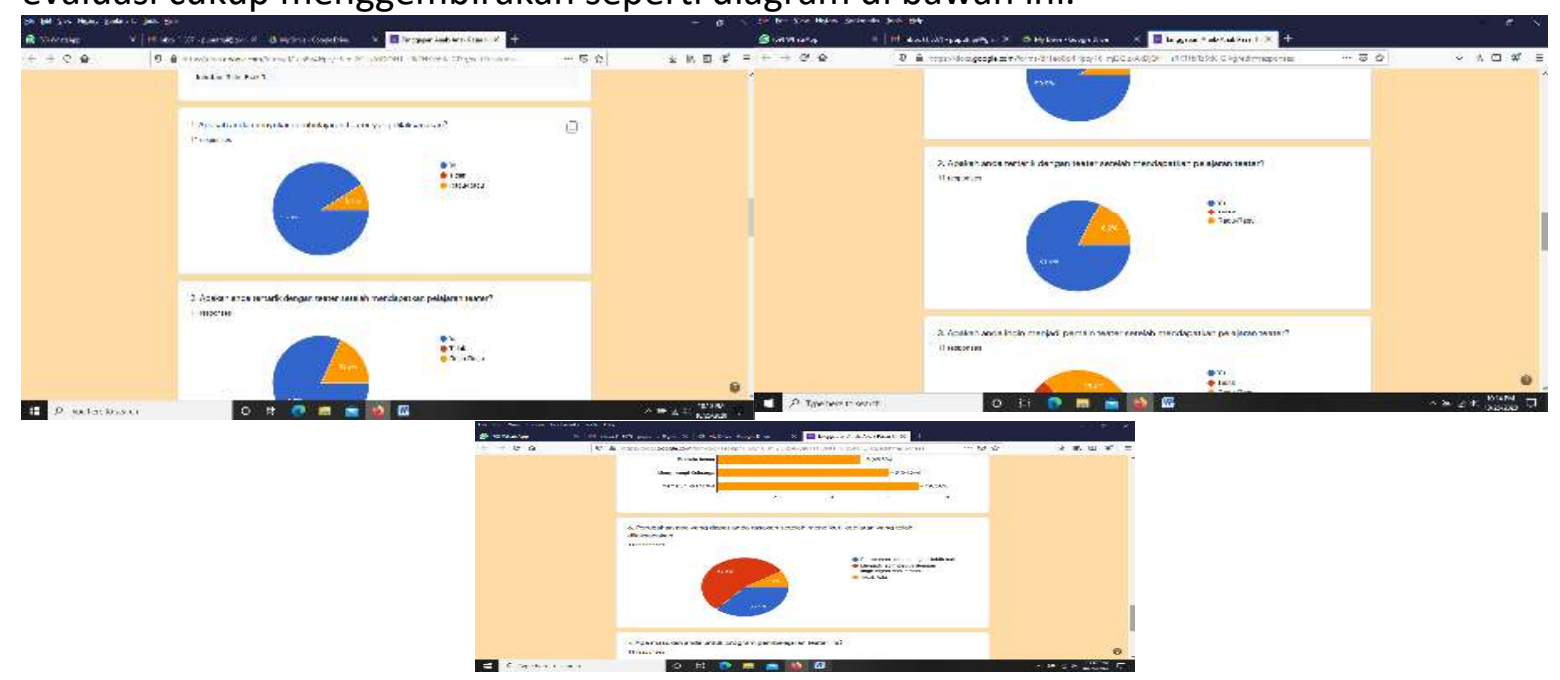

Berdasarkan hasil evaluasi, diketahui bahwa 90,9\% anak-anak menyukai pembelajaran mengenai teater, hanya 9,1\% menjawab ragu-ragu. Selanjutnya ditanyakan apakah mereka tertarik dengan teater setelah mengikuti kegiatan ini, 81,8\% anak-anak tertarik dengan teater 
hanya $18,2 \%$ yang menjawab ragu-ragu. Selanjutnya, mereka menjawab bahwa melalui kegiatan ini menjadi lebih peduli dengan lingkungan dan teman (54,5\%) dan perubahan sikap menjadi lebih baik (36, $4 \%$ ). Perubahan lebih baik juga dapat tim pelaksana lihat melalui sikap mereka selama berinteraksi dengan tim pelaksana. Sebelumnya, anak-anak pasar keramat sering bersikap kasar, tidak sopan serta berkelahi dengan teman-temannya. Namun, setelah pemberian materi, terlihat beberapa perubahan karakter. Seperti yang awalnya tidak menggunakan salam ketika berkomunikasi di grup, sekarang mulai menggunakan salam. Beberapa anak-anak pada awalnya juga sering berkata kasar di grup dengan temantemannya, namun sekarang mereka mulai menghargai temannya dan tidak berkata kasar lagi. Berdasarkan evaluasi yang dilakukan juga, terlihat anak-anak pasar keramat mempelajari beberapa nilai karakter dari kegiatan ini. Secara lebih rinci dapat dilihat pada diagram di bawah ini.

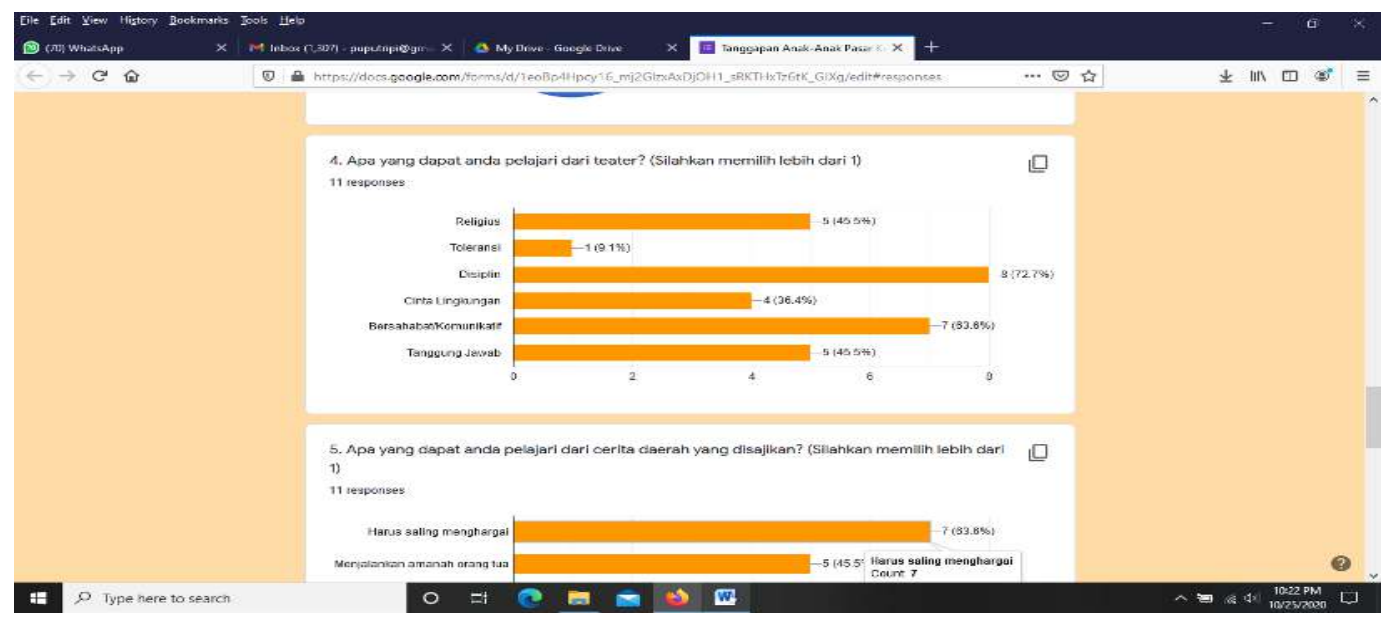

Selain itu, melalui audio sinematik cerita daerah khas Kabupaten Kotawaringin Timur yang diberikan juga memberikan pelajaran bagi anak-anak Keramat. Pelajaran yang mereka petik dapat dilihat pada diagram di bawah ini

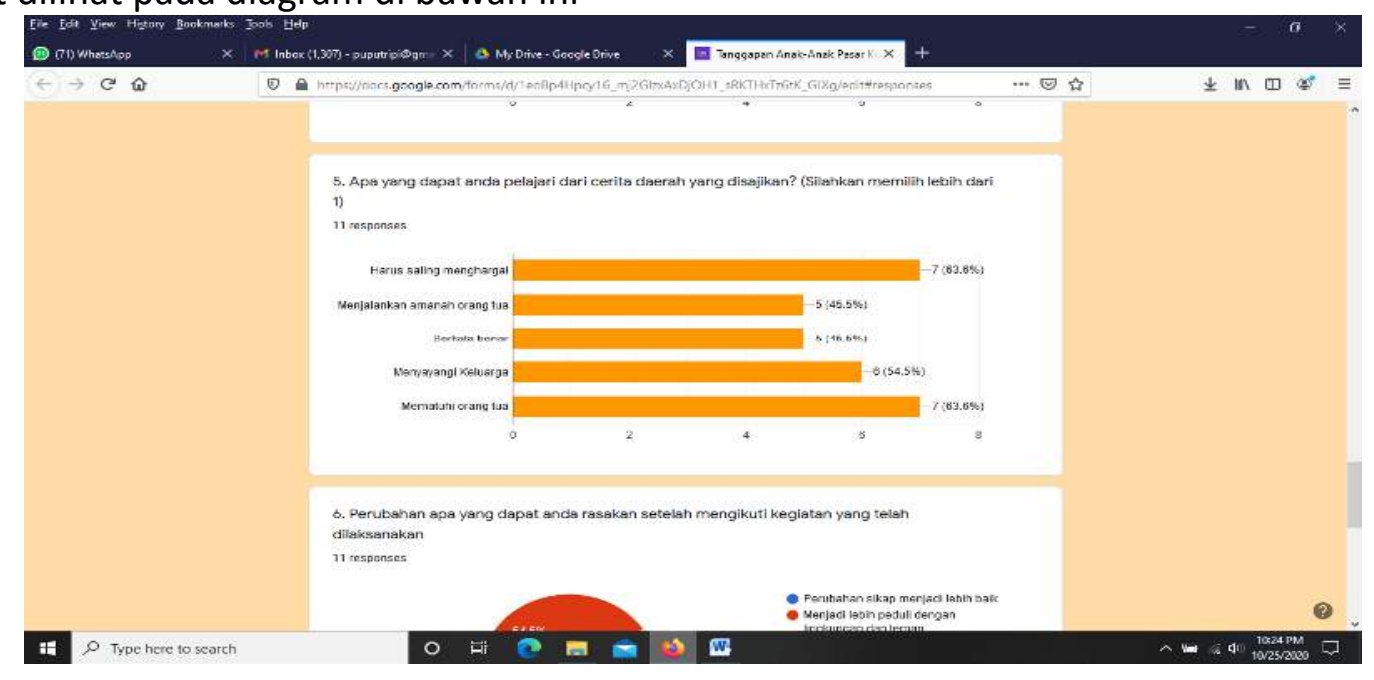

Berdasarkan kegiatan yang telah dilakukan dan respon yang diterima, dapat dikatakan bahwa kegiatan ini cukup berhasil. Meskipun dilakukan dengan sistem daring. Selain itu juga terdapat beberapa potensi yang dapat dikembangkan selanjutnya, yaitu:

1. Adanya komunitas teater di Sampit terutama berbasis kearifan lokal. Melalui kegiatan ini diharapkan kedepan akan muncul komunitas teater anak. Kegiatan ini juga didukung oleh 
dewan kesenian Kotawaringin Timur. Sehingga komunitas teater anak ini nanti dapat menjadi binaan dewan kesenian;

2. Video-video pembelajaran dapat digunakan sebagai video pembelajaran teater baik di sekolah maupun untuk komunitas-komunitas teater lainnya;

3. Kegiatan pengabdian masyarakat ini berpotensi untuk dijadikan model pengabdian masyarakat secara daring.

\section{KESIMPULAN}

Program pendidikan karakter melalui seni teater berbasis kearifan lokal untuk anakanak kampung kumuh pasar keramat sampit ini berdampak positif dan memberikan solusi terhadap masalah yang dialami anak-anak Pasar Keramat. Kegiatan ini juga dapat menjadi alternatif pembelajaran yang menarik bagi mereka di masa pandemi. Teater keramat dapat juga mewadahi dan mengasah potensi dalam diri serta pembentukan karakter bagi anak-anak pasar keramat. Program ini dapat menjadi salah satu model penanaman nilai-nilai karakter melalui seni teater serta model pengabdian masyarakat berbasis daring. Melalui program ini telah dihasilkan beberapa luaran yaitu buku pedoman pelaksanaan, kompilasi video pembelajaran, audio sinematik, serta artikel ilmiah. Program ini sangat diharapkan dapat dilanjutkan lagi dan dikembangkan menjadi lebih sempurna lagi dalam mengimplementasikan pendidikan karakter melalui seni teater.

\section{UCAPAN TERIMAKASIH}

Selesainya program ini dengan hasil sesuai yang diharapkan merupakan anugerah dari Allah SWT, Tuhan Yang Maha Esa. Tidak lupa pula ucapan terima kasih kami haturkan kepada berbagai pihak yang telah mendukung program ini, diantaranya yaitu :

1) Kementerian Riset dan Teknologi Pendidikan Tinggi yang telah memberikan kesempatan dan memberikan pendanaan;

2) STKIP Muhammadiyah Sampit yang telah mendukung, mengayomi dan memberikan arahan selama pelaksanaan program;

3) Anak-anak Pasar Keramat:

4) Dewan Kesenian Daerah;

5) Tokoh masyarakat/budayawan yang telah berperan besar dalam proses transfer ilmu pengetahuan terkait seni teater;

6) Media massa elektronik dan cetak yang telah membantu publikasi dan penyebarluasan informasi; serta

7) Seluruh pihak yang telah mendukung terselenggaranya program ini.

\section{DAFTAR PUSTAKA}

Eko Santoso, dkk. (2008). Seni Teater Jilid 1 Untuk SMK. Jakarta: Direktorat Pembinaan Sekolah Menengah Kejuruan.

Juned, S. (2012). Metode Latihan Teater Melalui Eksplorasi Psikologis. Jurnal Ekspresi Seni, 240.

Saleh, M. (1967). Sandiwara Dalam Pendidikan. Jakarta: Gunung Agung.

Srisudarso, M., \& Nurhasanah, E. (2018). Implementasi Pendidikan Karakter Pada Ekstrakurikuler Drama (Teater). Biormatika, 5. 
